REVUE DE L'INSTITUT

FRANÇAIS D'HISTOIRE

EN ALLEMAGNE

\section{Revue de l'IFHA}

Revue de l'Institut français d'histoire en Allemagne

$6 \mid 2014$

IFHA 6

\title{
L'Exzellenzcluster 243 : « La formation des ordres normatifs »
}

Université Goethe de Francfort-sur-le-Main

\section{Niels F. May}

\section{(2) OpenEdition}

\section{Journals}

Édition électronique

URL : http://journals.openedition.org/ifha/8020

DOI : 10.4000/ifha. 8020

ISSN : $2198-8943$

Éditeur

IFRA - Institut franco-allemand (sciences historiques et sociales)

Édition imprimée

Date de publication : 31 décembre 2014

ISSN : 2190-0078

\section{Référence électronique}

Niels F. May, "L'Exzellenzcluster 243 : «La formation des ordres normatifs » », Revue de l'IFHA [En ligne], 6 | 2014, mis en ligne le 31 décembre 2014, consulté le 20 avril 2019. URL : http:// journals.openedition.org/ifha/8020 ; DOI : 10.4000/ifha.8020

Ce document a été généré automatiquement le 20 avril 2019

(C)IFHA 


\title{
L'Exzellenzcluster 243 : «La formation des ordres normatifs "
}

\author{
Université Goethe de Francfort-sur-le-Main
}

\author{
Niels F. May
}

http://www.normativeorders.net/

Responsables : Prof. Dr. Rainer Forst et Prof. Dr. Klaus Günther

1 L'Exzellenzcluster 243 est consacré à la formation des ordres normatifs. Il réunit des chercheurs de plusieurs disciplines: histoire, philosophie, sciences politiquwes, droit, ethnologie, sociologie, économie et sciences religieuses. Créé en 2007, il est financé par la Deutsche Forschungsgemeinschaft jusqu'en 2017 et se trouve ainsi dans sa troisième et dernière phase. Il regroupe l'université Goethe de Francfort-sur-le-Main et d'autres centres de recherche de Fracfort, tels que l'Institut Frobenius, la Fondation hessoise pour la recherche sur la paix et les conflits, l'Institut für Sozialforschung de l'École de Francfort, l'Institut Max Planck pour l'histoire du droit mais aussi des institutions partenaires comme l'Institut Max Planck pour l'histoire du droit public étranger et pour le droit international (Heidelberg), le Centre for Research on Local Knowledge (Bamako, Mali) et la Technische Universität Darmstadt. La variété de ces institutions montre la portée inter- et pluridisciplinaire de cet Exzellenzcluster centré sur l'organisation des sociétés.

2 Il se divise dans sa forme actuelle en trois axes : le premier, «La normativité des ordres normatifs : genèse, points de fuite, performativité », vise à saisir la réflexivité progressive des ordres normatifs. Le deux, «La dynamique des ordres normatifs : bouleversement, changement, continuité », se focalise sur les transformations de longue durée et le troisième, «La pluralité des ordres normatifs: concurrence, interférence, interdépendance » analyse le côtoiement de plusieurs ordres normatifs.

3 L'ensemble regroupe 28 projets dont plusieurs concernent l'histoire de longue durée depuis l'Antiquité jusqu'au $\mathrm{xx}^{\mathrm{e}}$ siècle. On peut citer par exemple : « La politique impériale et l'espace des religions au $\mathrm{III}^{\mathrm{e}}$ siècle » (H. Leppin), « La Bible comme norma normans » (L. Schorn-Schütte), «La normativité du savoir formel: Sciences exactes, égalité et universalisme au XVIII ${ }^{\mathrm{e}}$ siècle» (M. Epple) ou encore l'«Iconologie de la science 
historique. La formation visuelle de la pensée historique aux $\mathrm{xIX}^{\mathrm{e}}$ et $\mathrm{Xx}^{\mathrm{e}}$ siècle » (A. Fahrmeir et B. Jussen). De plus, plusieurs projets s'interrogent sur la dimension historique des ordres normatifs, comme le projet «Légitimation par le droit des gens, légitimation du droit des gens » (S. Kadelbach et J. Steffek).

La perspective choisie par l'Exzellenzcluster privilégie une vision interne de l'établissement des ordres normatifs, en analysant en particulier les éléments narratifs leur servant de justification. L'« ordre normatif » est défini en tant que complexe de normes et de valeurs qui servent à légitimer la structure fondamentale d'une société, en particulier l'exercice du pouvoir politique et la distribution des ressources élémentaires nécessaires pour la vie. Il ne s'agit pas uniquement des normes existantes et appliquées dans les sociétés, mais également de normes transgressant l'ordre existant et le mettant en question. C'est pourquoi les ordres normatifs placent leur action dans une zone qui se situe toujours entre le passé, le présent et le futur. L'objectif est d'éviter une histoire linéaire et faire resurgir les lignes de conflit apparues lors de l'établissement des ordres normatifs à différentes époques. Une telle conceptualisation de l'ordre normatif doit permettre de réconcilier les différentes disciplines participant au projet.

Le site web de l'Exzellenzcluster permet d'accéder facilement à distance à plusieurs de ses publications ${ }^{1}$. La publication de leurs «papiers de travail» ("Working Papers») permet de suivre les progrès des différents projets. Plusieurs conférences sont mises en ligne sous forme de vidéos, qui permettent de participer à la réflexion de ce centre de recherche prolifique ${ }^{2}$. Il reste à espérer que sa production scientifique trouvera un public au-delà des frontières allemandes.

\section{NOTES}

1. http://www.normativeorders.net/de/component/publication/.

2. http://www.normativeorders.net/de/2013-11-11-15-48-04.

\section{AUTEUR}

\section{NIELS F. MAY}

(Université Goethe de Francfort/IFHA) 